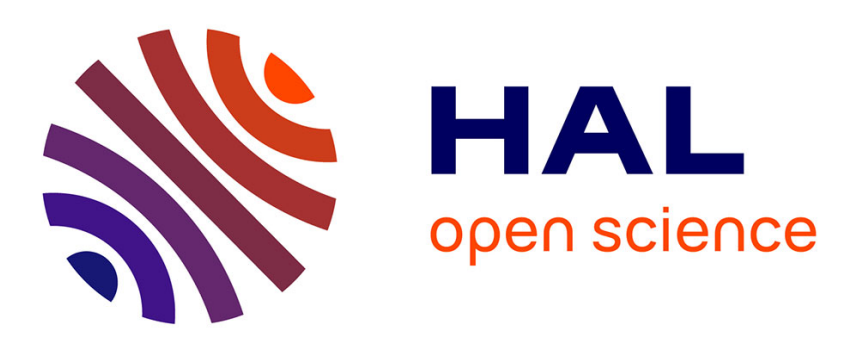

\title{
Design and simulation of printed winding inductors for inductive wireless power charging applications
}

David Jugieu, Alexandru Takacs, Guillaume Vigneaux, Mohammed Cheikh, S Kessler, R Benbouhout

\section{- To cite this version:}

David Jugieu, Alexandru Takacs, Guillaume Vigneaux, Mohammed Cheikh, S Kessler, et al.. Design and simulation of printed winding inductors for inductive wireless power charging applications. IEEE Wireless Power Transfer Conference, May 2015, Boulder, CO, United States. pp.1 4, 10.1109/WPT.2015.7140119 . hal-01409595

\section{HAL Id: hal-01409595 \\ https://hal.science/hal-01409595}

Submitted on 6 Dec 2016

HAL is a multi-disciplinary open access archive for the deposit and dissemination of scientific research documents, whether they are published or not. The documents may come from teaching and research institutions in France or abroad, or from public or private research centers.
L'archive ouverte pluridisciplinaire HAL, est destinée au dépôt et à la diffusion de documents scientifiques de niveau recherche, publiés ou non, émanant des établissements d'enseignement et de recherche français ou étrangers, des laboratoires publics ou privés. 


\section{Design and simulation of printed winding inductors for inductive wireless power charging applications}

\author{
D. Jugieu ${ }^{1}$, A. Takacs ${ }^{1,2}$ \\ ${ }^{1}$ CNRS, LAAS, 7 avenue du colonel Roche, F-31400 \\ Toulouse, France \\ ${ }^{2}$ UNIV de Toulouse, UPS, LAAS, F-31400, Toulouse, \\ France \\ djugieu@laas.fr, atakacs@laas.fr
}

\author{
G. Vigneau ${ }^{1,3}$, M. Cheikh ${ }^{3}$, S. Kessler ${ }^{3}$, R. \\ Benbouhout $^{3}$ \\ Continental Automotive SAS France \\ Toulouse, France
}

\begin{abstract}
Winding coils are key elements in the design and the implementation of an effective wireless power charging platform for wireless devices such as mobile phones, smart phones and tablet computers. Planar winding inductors are low-cost, ready to integrate with the electronics and fully compatible with a general printed circuit board (PCB) manufacturing process. This paper addresses the design and the simulation of the planar winding inductors in order to overcome some drawbacks of such structures concerning mainly the quality factor and the resistive/thermal losses.
\end{abstract}

Keywords-wireless power transfer; inductive antennas, charging platform; printed winding inductors

\section{INTRODUCTION}

Wireless power transmission (WPT) can be achieved by using near-field (inductive) or far-field (radiation) techniques. WPT techniques based on inductive coupling can be based on resonant or on non-resonant techniques. One of the most critical parts of an inductive WPT system is the inductive antenna/coil (IA). This IA should fit a limited size, provide a maximum intrinsic quality factor for an expected inductance with a magnetic coverage allowing an optimal energy transfer to the device to charge. IAs can be implemented by using wires (e.g. Litz coils) or directly printed on the circuit board (PCB IA). IAs based on Litz coil perform better from an electromagnetic point of view (better quality factor and efficiency) but are expensive. PCB IAs are cheaper and easy to integrate with the electronic cards but are subject to a lower efficiency, lower quality factor and a worst thermal dissipation behavior. This paper addresses the IAs design and simulation in order to provide optimal design guideline for frequencies in the range of hundreds of $\mathrm{kHz}$ according to Wireless Power Consortium (WPC) recommendations [1].

\section{PLANAR INDUCTIVE ANTENNAS}

Recently planar spiral IA was intensively studied in order to define design guidelines concerning mainly the impact of the geometry on quality factor as function of working frequency [2]. The intrinsic limitations of the inductive WPT systems using spiral IA as function of the power transfer efficiency was addressed in [3]. Those studies were based on analytical calculation [3] or electromagnetic simulation [2]. No measurement benchmark was presented in order to validate the simulation approaches. Moreover the impact of ferrite layer (usually used for shielding or to increase the inductance and the quality factor) was not addressed.

\section{A. Simulation technique and correlation with the experimental results}

A full-wave electromagnetic simulation technique by using FEKO [4] or HFSS [5] software was adopted. This approach exhibits several advantages: (i) coupling effects, PCB impact and ferrite layers can be taken into account (note that ferrite layers are sometimes necessary for shielding or for increasing the quality factor); (ii) IAs manufactured on a multilayer PCB (2 to 8 layers) can be simulated; (iii) circuital parameters (input impedance, inductance, loss resistance, quality factor, etc.) and electromagnetic (magnetic field) can be computed directly; (iv) other antennas such as NFC or GSM antennas can be further added and simulated using the same software. The major drawback is the simulation time that can be excessive. Nevertheless this drawback was overcome by using a cluster (parallel computing).

\section{B. Correlation with the experimental results}

A prototype (already manufactured and characterized) available at Continental Automotive Toulouse was retrosimulated inside FEKO and HFSS in order to check the validity of the proposed approach. This benchmark structure (BS) manufactured on a square FR4 PCB (60 mm wide, substrate thickness $h=1.6 \mathrm{~mm}$ ), consists of a hollow spiral (Fig. 1) with following geometrical parameters: metallization thickness $\mathrm{t}=35 \mu \mathrm{m}$, inner radius $\mathrm{Ir}=10.5 \mathrm{~mm}$, outer radius $\mathrm{Or}=21.85 \mathrm{~mm}$, turns $n=10$, cooper strip width $w=0.85 \mathrm{~mm}$, gap between strips $\mathrm{g}=0.2 \mathrm{~mm}$. It's a two layers structure with two identical hollow spirals located on top and on bottom side of the PCB. BS was simulated alone (Fig $1 \mathrm{a}$ ), two BSs in face to face configuration (Fig 1b), 2 BSs in face to face configuration with a shielding ferrite layer placed outside (Fig 1c).
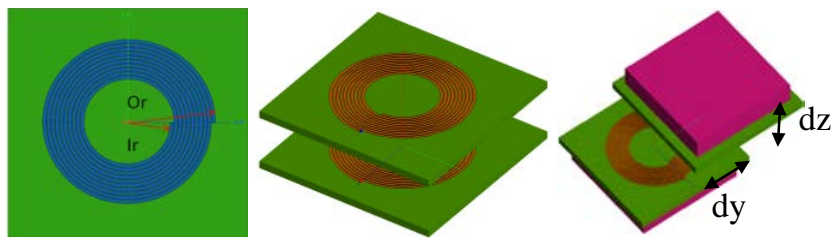

Figure 1. Benchmark structures: a) IA only (top view), b) two IAs, c) two IAs shielded by a ferrite 
A square ferrite $\mathrm{L} 7 \mathrm{H}$ (52 $\mathrm{mm}$ wide, thickness $\mathrm{hf}=3 \mathrm{~mm}$, gap between ferrite and PCB: $g f=1 \mathrm{~mm}$ ) from TDK [6] was used for the structure represented in Fig $1 \mathrm{c}$. The following simulation approaches were adopted inside FEKO [4]: (i) MoM-VEP (Method of Moment, Volume Equivalence Principle) (ii) MoM-GF (Method of Moment, Green Function approach) and (iii) MoM-FEM (Method of Moment, Finite Element Method). Note that: (i) MoM-FEM is a hybrid simulation technique: metallic layers are simulated by using MoM while the dielectric and magnetic layers are simulated by using FEM, (ii) MoM-GF supposed that the dielectric layers are infinite in horizontal plane and magnetic and dielectric layers cannot be combined inside the same model, (iii) double precision numerical format with low frequency stabilisation was activated for MoM-FEM. Inside HFSS (FEM), a 2D or 3D approach was used to simulate the copper metal plating (results are quasi identical). The obtained simulation results were directly compared with the measurements (input impedence at $110 \mathrm{kHz}$ ). The generated magnetic field (numerically computed/simulated in an grid point sourrounding the IA) cannot be easily measured (experimental setup requires a calibrated coil; its dimension is prohibitive and can perturb the measured magnetic field; a precise systems for coordinate measurement is also required). Thus an indirect technique was adopted. Insteed of performing a magnetic field measurement, we evaluated the voltage coupling factor between two indentical IAs ( $k=V$ _out $/ \mathrm{V}$ in; where $\mathrm{V}$ _in is the voltage injected in the primary IA and V_out is the voltage measured/induced in the secondary IA). Experimental and simulation results are depicted in Table I. From input impedance (Zin) values reported in Table I, usefull quantities (inductance: L, quality factor : Q or thermal losses, etc.) can be derived. We remark that the correlation between measurement and simulation is very good. As shown in table I, FEKO (VEP or FEM approach) or HFSS (FEM) simulation can be used in order to simulate our structure.

TABLE I. EXPERIMENTAL AND SIMULATION RESULTS FOR BS

\begin{tabular}{|c|c|c|c|c|c|}
\hline \multirow{2}{*}{$\begin{array}{c}\text { Without } \\
\text { ferrite }\end{array}$} & \multicolumn{4}{|c|}{ Simulation } & \multirow{2}{*}{ Measurement } \\
\cline { 2 - 5 } & VEP & $\begin{array}{c}\text { FEKO } \\
\text { FEM }\end{array}$ & $\begin{array}{c}\text { FEKO } \\
\text { GF }\end{array}$ & $\begin{array}{c}\text { HFSS } \\
\text { FEM }\end{array}$ & \\
\hline $\operatorname{Re}($ Zin) $\Omega$ & 1.212 & 1.289 & 1.149 & 1.278 & 1.28 \\
\hline $\operatorname{Im}($ Zin) $\Omega$ & 10.36 & 11.71 & 9.98 & 10.4 & 10.02 \\
\hline $\begin{array}{c}\text { With } \\
\text { ferrite }\end{array}$ & & & & & \\
\hline $\operatorname{Re}($ Zin) $\Omega$ & 1.22 & 1.37 & $\mathrm{NC}^{*}$ & 1.45 & 1.33 \\
\hline $\operatorname{Im}($ Zin $) \Omega$ & 16.87 & 15.83 & NC* $^{*}$ & 16.85 & 16.31 \\
\hline
\end{tabular}

A 25\% variation (25\%) of ferrite relative magnetic permeabilitty (standard value $\mu \mathrm{r}=800$ ) was taken into account for simulation: no major impact on input impedance was observed. The voltage coupling factor (simulated and measured) obtained with two typical loads: $10 \mathrm{M} \Omega$ (for an open circuit) and $3 \Omega$ (for a battery) is shown in Fig. 2 and Fig. 3 respectively. A good correlation between simulation and measurement was observed proving that magnetic field is well computed. The magnetic field distribution simulated for one IA with a ferrite positioned behind is represented in Fig. 4 and Fig. 5 respectively. We note that the shielding effect of the ferrite is well illustrated (the magnetic field for negative $\mathrm{z}$ coordinates is very week).

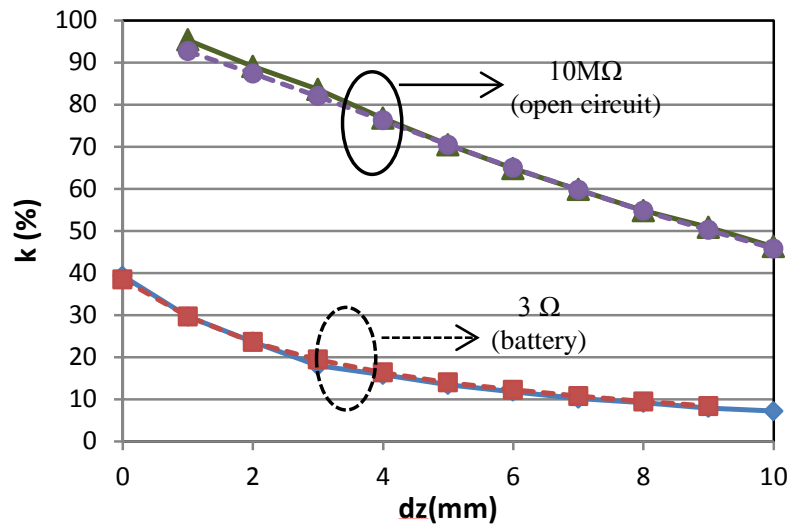

Figure 2. Measured and simulated coupling factor for BS as function of vertical distance $(\mathrm{dz})$ between two IAs sourrounded by ferrite (Fig. $1 \mathrm{c}$, dy=0 $\mathrm{mm})$. Measurement (continous line) with $3 \Omega$ load (diamond marker) or with $10 \mathrm{M} \Omega$ load (triangle marker). Simulation (FEKO, dotted line) with $3 \Omega$ load (square marker) or with $10 \mathrm{M} \Omega$ load (circular marker)

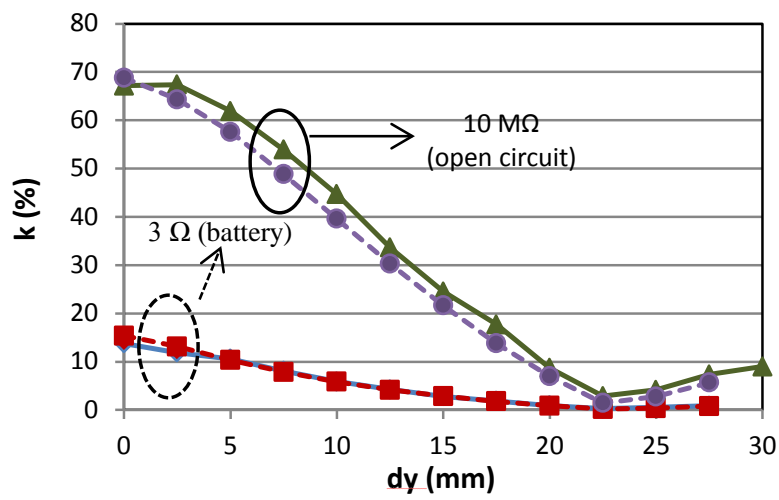

Figure 3. Measured and simulated coupling factor for BS as function of horizontal misalignement (dy) between two IAs surrounding by ferrite (Fig. 1 $\mathrm{c}, \mathrm{dz}=5 \mathrm{~mm}$ ). Measurement (continous line) with $3 \Omega$ load (square marker) or with $10 \mathrm{M} \Omega$ load (triangle marker). Simulation (FEKO, dotted line) with $3 \Omega$ load (square marker) or with $10 \mathrm{M} \Omega$ load (circular marker)

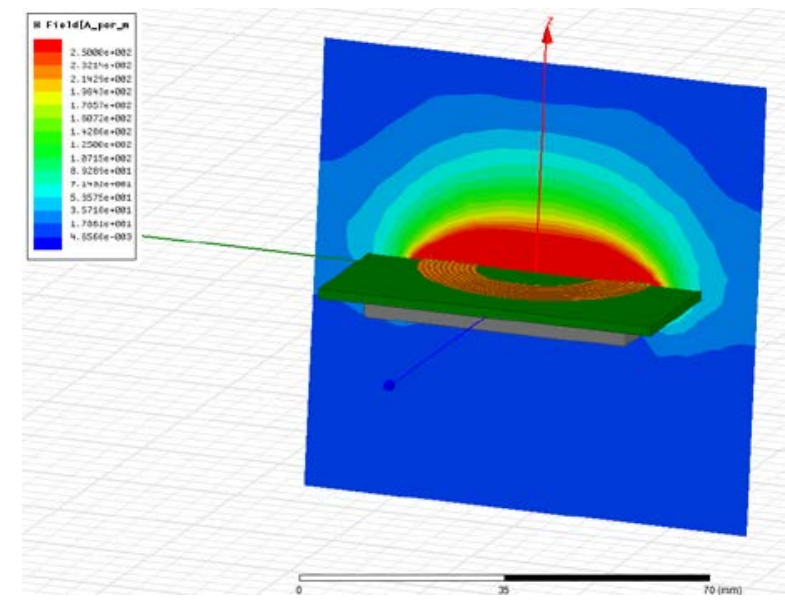

Figure 4. The magnetic field distribution (scalar plot) obtained for one IA with a ferrite positionned at a distance $\mathrm{d}=1 \mathrm{~mm}$. 


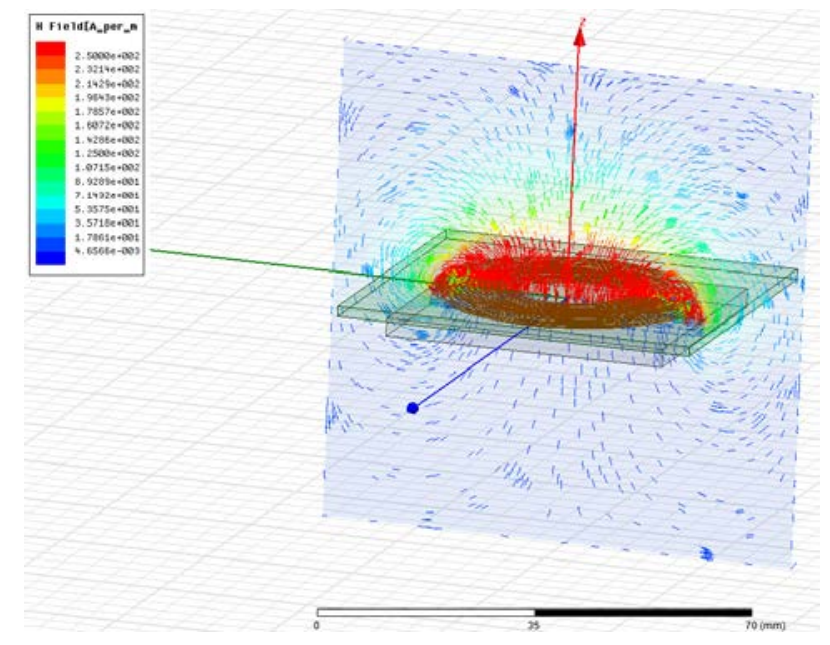

Figure 5. The magnetic field distribution (vectorial plot) obtained for one IA with a ferrite positionned at a distance $\mathrm{d}=1 \mathrm{~mm}$.

Additional simulations were also performed on octagonal or rectangular (square) hollow IAs by varying the width trace, the gap between neighboring traces, the number of turns and the size of the inner hollow. Intensive electromagnetic simulation conducted to the following conclusion:

(i) at $110 \mathrm{kHz}$, the resistive part of the input impedance is mainly a DC resistance (coming from the metallic trace length), the AC effects caused by skin depth (computed skin depth is around $0.2 \mathrm{~mm}$ ), coupling and proximity effects can be neglected. The impact of PCB layer can be neglected (at least for bi-layer structures).

(ii) from a system point of view a minimal value of inductance should be assured with a quality factor as high of possible in a fitted size design. Supposing that size is always limited it is no reason to increase trace width far beyond skin depth because metal plating thickness is usually $35 \mu \mathrm{m} / 70 \mu \mathrm{m}$. It is better to keep width in the range of skin depth (width ' $w$ ' should not exced 2 to 3 times the skin depth) to diminish gap size ' $g$ ' within manufacturing tolerances and to increase the numbers of turns. Thus the total length of metallic strip is minimized and quality factor is enhanced. Quite similar conclusion was reported in [3]. Input impedance resistive part can be minimized also by using planar Litz structures [7].

(iii) as expected ferrite increases IAs inductance and quality factor and it is mandatory to include it into IA simulation model. Variation of its relative magnetic permeability in the range of the manufacturing tolerances (25\%) does not impact significativelly IAs behavior.

(iv) coupling between two identical IAs decreases when misalignment increases.

Works are under run in order to improve DC to DC efficiency of wireless power charging system according with WPC recommendation [1],[3].

\section{CONCLUSION}

The use of full wave electromagnetic simulation in order to predict IAs performances was demonstrated. A good correlation between numerical and experimental results was obtained on electrical (input impedance) and electromagnetic (magnetic field) quantities. Based on electromagnetic simulation design guidelines were derived. Minimize wire length (metallic trace), keep inductance and quality factor as high as possible (by increasing the number of turns and by reducing the gap between metallic strips within manufacturing tolerances) are the key points to design an effective IA for an efficient wireless power charging system at low frequencies (in the range of $110 \mathrm{kHz}$ ).

\section{ACKNOWLEDGMENT}

This work was supported by Continental Automotive SAS France through "Electromagnetic simulation and modeling research activities for inductive wireless power charger application" contract.

\section{REFERENCES}

[1] http://www.wirelesspowerconsortium.com/

[2] Y. Su.; X. Liu; C. K. Lee; S.Y.R Hui, "On the Relationship of Quality Factor and Hollow Winding Structure of Coreless Printed Spiral Winding (CPSW) Inductor", IEEE Trans. on Power Electronics, Vol. 27, Issue 6, pp. 3050-3056.

[3] E. Waffenschmidt, "Wireless power for mobile devices", in Proc. of 2011 IEEE Telecommunications Energy Conference (INTELEC), 2011, pp. 1-9.

[4] www.feko.info

[5] http://www.ansys.com/Products/Simulation+Technology/Electromagneti cs/High-Performance+Electronic+Design/ANSYS+HFSS

[6] TDK: Ferrite cores for EMI Suppression available at: datahttp://www.tdk.co.jp/tefe02/e9b44_t.pdf

[7] Shen Wang, M. A. de Rooij, W. G. Odendaal, J. D. van Wyk, and D. Boroyevich, "Reduction of high-frequency conduction losses using a planar litz structure," IEEE Trans. Power Electron., vol. 20, no. 2, pp. 261-267, Mar. 2005. 